\title{
Uma Pragmática dos Fedores: vertigens ciborgues entre o ralo e o Lixão de Gramacho
}

\section{A Pragmatics of Stinks: cyborgs dizziness between the drain and Gramacho's Dump}

Resumo:

Tomando uma transversal entre os filmes O Cheiro do Ralo e Estamira problematizamos os modos de subjetivação nas cidades contemporâneas, buscando escapes às estratégias hegemônicas de controle, a partir da ativação do que denominamos subjetividade-ciborgue em sua potência estética de criação de mundos. A partir da proposição de que na sociedade de controle somos todos híbridos, ciborgues pós-humanos, cabe indagar se desejamos, como Lourenço, protagonista do filme de Heitor Dahlia, viver/morrer entorpecidos pelo cheiro do ralo, fedor que emana das tripas do capitalismo, ou se, inspirando-nos em Estamira, personagem do documentário de Marcos Prado, construiremos do, no e com o Lixo modos de existência capazes de afirmar a vida.

Palavras-chave: Subjetividade. Ciborgue. Sociedade de controle.

\section{Abstract:}

Taking a cross between the movies The smell of the drain and Estamira, we put in question the modes of subjectification in contemporary cities, seeking to escape the hegemonic control strategies through the activation of which we call subjectivity-cyborg in its aesthetic potency to create worlds. Based on the proposal that in the society of control we're all hybrids, post-human cyborgs, it's better ask if we want, as Lourenço, Heitor Dahlia's protagonist, live/die weighed down by the drain smell, stink from the tripes of capitalism, or whether, inspired by Estamira, character of Marcos Prado's documentary, we will build in, from and with the Trash, existence's modes abled to affirm life.

Keywords: Subjectivity. Cyborg. Society of control.
SANTOS, Adriana Rosa Cruz. Uma Pragmática dos Fedores: vertigens ciborgues entre o ralo e o Lixão de Gramacho. Informática na Educação: teoria \& prática, Porto Alegre, v. 13, n. 2, p. 26-37, jul./dez. 2010.

\section{Adriana Rosa Cruz Santos \\ Universidade do Estado do Rio de Janeiro}

\section{Introdução}

É fácil fazer corresponder a cada sociedade certos tipos de máquina, não porque as máquinas sejam determinantes, mas porque elas exprimem as formas sociais capazes de Ihes darem nascimento e utilizá-las. (DELEUZE, 1992a, p. 221)

0 cheiro que se espalha, impregnando e preenchendo espaços, não é puro. Constituído de dejetos, sentidos e putrefações, o cheiro do ralo, além de ser resultante do esgoto diário, é também o que engendra o protagonista, suas questões e inquietações. Esta simultaneidade, que faz do cheiro do ralo tanto causa como efeito, acaba por nos lançar numa circularidade mortífera. Tudo começa e termina no ralo. É o cheiro do ralo que desestabiliza Lourenço, trazendo certa inquietude ao que parecia forjado de pequenas e decisivas certezas. Termina-se o filme nauseado pela cela-forte que é o cotidiano de Lourenço: nessa sucessão de cenas, só parece haver espaço para a reinscrição repetitiva de um eu que agoniza e goza num a-topos, a loja de objetos destituídos de história. A loja de objetos-mercadorias recusa a história e qualquer conexão com a vida da cidade. Fora do tempo e do espaço, misturam-se no filme figurinos e objetos que podem ser de qualquer época, 
constituindo este não-lugar. Assim, temos a ilusão de que é possível prescindir da cidade, pois como afirma Lourenço referindo-se à loja, "[...] aqui tem tudo que o mundo pode oferecer [...]" (O CHEIRO..., 2007).

Lourenço é o dono de um curioso negócio, aonde as pessoas vêm vender seus objetos, normalmente em momentos de dificuldade financeira. Não parece ser exatamente um brechó, pois os objetos comprados pelo mercador não são colocados a venda. O cenário aproxima-se mais de uma loja de penhores - sem direito a estorno - onde fragmentos da vida dos personagens são convertidos em mercadoria e acondicionados nas prateleiras. Certo dia, Lourenço é tomado pela visão de uma bunda numa lanchonete próxima e faz de tudo para possuí-la, para também convertê-la em mercadoria. Tal operação, o coloca em contato com a dona da bunda, garçonete, que na história não tem nome, nem rosto: doravante reduzida à parte de sua anatomia, a moça também vende ao mercador o que ele deseja. Paralelamente, o ralo do banheiro passa a exalar um mal cheiro que constrange Lourenço diante de seus clientes e a luta para exterminar o cheiro do ralo, até finalmente ser vencido por ele, é o pano de fundo da história.

O Cheiro do Ralo (2007) asfixia pela ausência de cidade, aqui entendida como a máquina que opera bifurcações, proliferações de sentido, encontros com o outro e com o mundo. A cidade que entra pela porta de ferro da rua desabitada é sobrecodificada pelo capital e tudo vira mercadoria. Aqui não há lugar para a história. O que vem do ralo é o mundo que retorna para o bunker de Lourenço, cheirando à merda. É este mundo-cidade, irredutível ao estriamento produzido pelo capital $^{1}$ que nauseia Lourenço, já que embaralha a monótona e repetitiva redução de objetos, histórias e pessoas a seu valor de troca.

Misturado aos dejetos e objetos, Lourenço é um ciborgue marrom do capitalismo contemporâneo, cheirando a mofo disciplinar. Carcereiro dos fragmentos de história expurgados de seu contexto, ele é prisioneiro da passagem, dos entretempos que constituem sociabilidades e subjetividades híbridas, em um ce-

1 Nelson Brissac Peixoto, inspirando-se livremente em Mil Platôs, de Deleuze e Guattari, concebe a cidade como um "[...] espaço estriado pela moeda, pelo trabalho e pelo capital [...]" (PEIXOTO, 2002, p. 100), um espaço recortado e fixado por essas categorias. nário no qual parece não haver mais qualquer exterioridade possível.

Longe da cidade fortemente segmentarizada, vivendo em seus interstícios, em seus intestinos, encontramos outro cheiro. Fedor, também. Mas um mal-cheiro pestilento, capaz de nos libertar de nós-mesmos, fazendo-nos misturar à multidão. Legião é o seu nome. 0 diabo aqui não nos leva para as profundezas do ralo, mas nos faz conspirar ${ }^{2}$ com Estamira contra todos os espertos ao contrário, os que habitam o Céu da Plenitude ou os que labutam e vivem como esmerados copiadores. Estamira não é um eu, é uma existência que se constitui nos embates e nas composições de seu corpo com o desta cidade múltipla, que atravessa Campo Grande, Goiás Velho, Engenho de Dentro e Gramacho, só pra citar alguns pontos de ancoragem desta cidade-mundo. Os territórios percorridos não se restringem às fronteiras geográfico-administrativas, mas antes as fazem ranger, as deslocam, as reinventam, em favor de uma vida que é proliferação.

Estamira é uma mulher de meia idade que cata lixo em um grande depósito de lixo, a céu aberto, na região metropolitana do Rio de Janeiro. $O$ documentário de mesmo nome registra o cotidiano desta mulher, que combina de forma ímpar loucura e lucidez, em meio à miséria, às dificuldades familiares, à camisa-deforça química dos psicotrópicos, que a fazem sentir sua cabeça em efervescência contida, como um copo de Sonrisal. É no meio do Lixo que Estamira faz amigos, ganha o que precisa para sua sobrevivência - "Dinheiro? Eu faço!" (ESTAMIRA, 2006), constrói um cotidiano nas bordas da psiquiatria, esquivando-se do raloidentitário de doente mental.

O ar que falta lá, na loja de penhores, sobra aqui. O fedor do Lixão de Gramacho, assim como o desfile de cadáveres, urubus e desperdício, não sufocam. Talvez seja porque nos apresentam um pouco de possível ${ }^{3}$, uma brecha que expande a vida lá onde pareceria menos provável: no meio do lixo. E é no lixo que Estamira inventa para si - e ao fazê-lo, afirma esta possibilidade para o mundo - uma vida.

Estamira também é ciborgue como Lourenço, mas de outro tipo. Não é marrom, mas

2 Conspirar seria, segundo Guattari (1987a), respirar junto...

3 "Um pouco de possível, senão eu sufoco [...]", disse Deleuze (1992, p. 131) ao falar de Foucault, em entrevista a Claire Parnet. 
furta-cor. O fedor pelo qual transita faz delirar outro mundo, abre o real para a transmutação em campos de possíveis inusitados, enquanto os fedores do ralo asfixiam, convertem qualquer coisa em objeto de consumo esvaziado de história e de geografia. Na loja de penhores de Lourenço tudo é reduzido à condição de objeto de qualquer lugar, de qualquer tempo, ao perder as marcas impressas nos corpos pelas relações e histórias e ganhar um espaço oco nas prateleiras. No Lixão de Estamira as fronteiras são esgarçadas para além dos além, virtualizando o real para novas ficções, constituindo híbridos de cidade, subjetividade, vida.

O presente artigo se propõe a pensar as relações entre sociedade de controle, a cidade e os novos modos de subjetivação contemporâneos, a partir de dois filmes: O Cheiro do Ralo (2007), de Heitor Dhalia e Estamira (2006), de Marcos Prado. O Cheiro do Ralo é uma obra de ficção, baseada no romance homônimo de Lourenço Mutarelli e Estamira é um documentário sobre a vida de uma mulher que ganha a vida no Lixão de Gramacho, na Baixada Fluminense. Ambas as narrativas se desenrolam a partir de um personagem - Lourenço e Estamira - e nos lançam, de modos distintos, na problematização das relações entre a vida na sociedade de controle, tal como propõe Deleuze, e os processos de subjetivação que Ihe são imanentes. Estamira, catadora de lixo e louca nos apresenta sua vida, indissociável da vida da cidade, do mundo que habita. Lourenço, síntese trágica dos modos de subjetivação capitalísticos ${ }^{4}$, nos lança em uma vida regulada pela lógica do capital, onde tudo - inclusive a cidade - se converte em mercadoria.

Emerge neste interstício a idéia de uma subjetividade-ciborgue, subjetividade híbrida, que encerra tanto possibilidades de ruptura com o modo capitalístico de existência, como de acoplamento ilimitado. Justamente por ser desnaturada, mutante e sem árvore genealógica precisa, a subjetividade-ciborgue condensa os riscos e as possibilidades de fabricação de um outro tempo.

A idéia é trabalhar com cada um desses per-

4 Definiremos a expressão subjetividade capitalística no Take 2. sonagens como singularidades que explicitam o campo de forças que os constituíram. Nesse jogo, é na raridade da existência de cada um desses personagens infames ${ }^{5}$ que é possível acompanhar as linhas que os teceram e as reapropriações ou rupturas que forjaram.

\section{Take 1: Sociedade de Controle e Cidade-Mundo}

Para Deleuze (1992a), a sociedade de controle sucede a sociedade disciplinar, tal como proposta por Foucault (1989a). Não se trata exatamente de superação, mas de expansão, ampliação de um modo de funcionamento que objetiva maximizar a produtividade, a eficácia, ao mesmo tempo em que minimiza a potência política dos corpos. Tal expansão, entretanto, procede por outros meios e estratégias, imanentes às transformações em curso no mundo capitalista.

Assim, ainda que se trate dos mesmos objetivos - docilidade política e eficácia produtiva - sociedade disciplinar e sociedade de controle operam através de diferentes meios, constituindo modos diversos de gestão dos corpos, dos espaços e dos fluxos.

A passagem de um modo de segmentarização do socius a outro é marcada pela crise generalizada dos meios de confinamento: o controle não se dá mais por meio das instituições sociais modernas - a família, a escola, o hospital, a fábrica - mas opera a céu aberto e tem na mídia seu principal aliado. Esse controle sem fronteiras definidas, que ganha corpo através dos deslocamentos e mutações, atua por modulações, em lugar das modelagens produzidas pela disciplina. Não temos mais o molde-indivíduo, forma fixa, identitária, passível de ser localizado/reconhecido através da assinatura, lastro identitário-disciplinar, mas divíduos, que são acessáveis através de senhas, banco de dados ou posição nas infinitas

5 Foucault (2003) criou a expressão homens infames para designar personagens reais, sem fama alguma, que foram subitamente iluminados pelo poder e que, graças ao acaso das lutas, retornaram das sombras e da poeira de um passado materializado em documentos, ordens de prisão, sentenças, para um presente sem futuro certo, pelas mãos de algum pesquisador errante. Esses homens infames, mais que representar seu tempo, se opõem, em uma perspectiva foucaultiana, a qualquer forma de redução a um sistema explicativo e possibilitam entrever os jogos de força em um momento singular. 
redes que se entrecruzam, constituindo o tecido social.

Numa sociedade disciplinar, atrelada ao espaço físico, um indivíduo era referenciado através de seu endereço postal, que remetia a um lugar físico que não era mais que um ponto numa rede geográfica de longa duração. Hoje, um habitante se define como inscrito numa rede variável, onde a prova de domicílio não é mais o título de propriedade ou o pagamento de aluguel, mas a fatura de água, de eletricidade ou gás, de telefone etc. É nossa inscrição nessas redes, nosso estatuto de consumidor de fluxos técnicos, que servem como prova jurídica de nosso pertencimento espacial. [...] Somos definidos humanamente como membros de múltiplas redes. (COSTA, 2006, p. 44)

No capitalismo de sobreprodução contemporâneo, voltado para o consumo, a empresa substitui a fábrica e, como diz Deleuze (1992a, p. 221), "[...] a empresa é uma alma, um gás [...]". Se como afirmou o filósofo francês na epígrafe deste artigo, a cada sociedade corresponde um tipo de máquina, a que máquina(s) corresponderia a sociedade de controle? Ele afirma que nessa sociedade os computadores, as máquinas informáticas Ihe são correspondentes, máquinas que apontam simultaneamente para uma evolução tecnológica e para uma mutação do capitalismo.

Façamos ranger o filósofo, tendo como intercessor o conceito de máquina, proposto por ele e Guattari, vinte anos antes, no primeiro tomo de Capitalismo e Esquizofrenia, o livro O Anti-Édipo. Aqui a noção de máquina, proposta por Deleuze e Guattari (1976), define-se como um sistema de cortes, no qual as máquinas encontram-se articuladas umas às outras: "[...] qualquer máquina é corte de fluxo em relação àquela com que está conectada, e é fluxo ou produção de fluxos em relação à que está conectada com ela." (DELEUZE; GUATTARI, 1976, p. 40) Esta noção possibilita pensar processos de interação transversais e mútuas determinações entre diferentes níveis de organização da vida, como os planos técnicos, da subjetividade e o plano das formas sociais.

Os novos tempos constituem novas espacialidades, novos modos de habitar e se relacionar com os territórios. Como se configura o espaço urbano nas sociedades de controle? Em que cidades vivemos, amamos, nos relacionamos, morremos?

Tomamos aqui a cidade não como mero efeito espacial das transformações que emer- gem com a modernidade e o capitalismo, em consonância com as novas formas de produção material e organização social. A cidade para nós não é uma espécie de cenário no qual se desenrola a vida hoje, para boa parte da população mundial. Pensamos a cidade como uma máquina, cujo contorno e movimentos são dados pelas diferentes conexões postas em funcionamento por seus habitantes e por outras máquinas que incessantemente a recortam, a codificam, a deslocam: o mercado, o Estado, o capital. A esse respeito, nos fala Milton Santos:

O problema se localiza nas cidades, mas é equívoco tratá-lo como questão urbana. Equívoco e enganoso. A questão é muito mais que urbana: é urbana e rural; é local, estadual e federal; é nacional e internacional. Podemos dizer que estruturalmente a crise é muito mais uma crise na cidade do que uma crise da cidade. (SANTOS, 2002, p. 125)

Seguindo a proposição de Milton Santos, ousaríamos falar em uma cidade-mundo, já que a cidade é ponto de convergência e articulação de diferentes fluxos: econômicos, semióticos, subjetivos, materiais, políticos, etc. E é o modo como são agenciados esses fluxos que lhe confere um corpo sempre provisório, posto que se transforma ao sabor das conexões que vão se fazendo.

Cabe ressaltar que a máquina só opera por agenciamentos, ou seja, conectada a outras tantas máquinas, sejam elas concretas ou abstratas. Essa máquina complexa, essa megamáquina que é a cidade (GUATTARI, 1992) se define por seu caráter político, ou seja, por sua potência de produzir modos coletivos de viver.

O que conta, com as cidades de hoje, é menos os seus aspectos de infra-estrutura, de comunicação e de serviço do que o fato de engendrarem, por meio de equipamentos materiais e imateriais, a existência humana sob todos os aspectos em que se queira considerá-las (GUATTARI, 1992, p. 172).

Convivem na cidade modos de vida díspares, contrastantes, que compõem uma tessitura urbana polifônica e múltipla. Os riscos de homogeneização plastificada advêm dos modos de funcionamento que tendem a otimizar alguns fluxos - de capital, de consumo - e limitar tantos outros, em especial os que desestabilizem o já instável funcionamento ca- 
pitalista. Desta forma as cidades tendem a se assemelhar cada vez mais a aeroportos, com os meios de interceptação imanentes à sua própria constituição (VIRILIO, 1993).

Não são necessárias cercas para limitar o acesso ou ordens para regular a circulação dos diferentes grupos sociais na cidade, ainda que recentemente o governador do estado do Rio de Janeiro tenha proposto construir muro nas favelas, a fim de preservar áreas de Mata Atlântica ${ }^{6}$. O esquadrinhamento da cidade está vivo em nossos corpos e não são necessários obstáculos físicos ou leis para sabermos quem pode freqüentar os shopping centers ${ }^{7}$ dos bairros de classe média-alta ou os mercados populares, como o Mercadão de Madureira...

Assim, esquivando-se da cidade, protegendo-se do contato com o estranho ou usando-a como amplificadora dos movimentos de afirmação de uma vida coletiva, todos, de um jeito ou de outro, nos articulamos a esta megamáquina. Caberia, talvez, aprender as astúcias de como fazê-la delirar, inventar becos com incontáveis saídas, desmanchar as fixações. Viver ( $n$ )a cidade como zona de guerra:

Nas cidades usadas como zona de guerra, nada está concluído ou perdido definitivamente. A paz não é bem vinda, porque a alteridade, em sua radicalidade tensa, desacomoda, perturba, à semelhança da politização da arte criadora de intensidades inesgotáveis de sentidos, diluindo compactas e irrefutáveis formas de eu e nós. Nas cidades como campo de combate, podemos fazer da insurgência um ato criativo [...]. Nessas cidades, a afirmação da vida não nos dá sossego. Nada está em paz, concluído, definitivamente perdido. No desassossego, virtualidades de resistências podem enfrentar o mórbido desencanto celebrado pelo capitalismo do momento. (BAPTISTA, 2004, p. 9)

60 assunto foi largamente divulgado pelos meios de comunicação entre abril e maio de 2009. Dentre algumas fontes possíveis sobre o tema, podemos citar o Jornal Folha de São Paulo (http://www1.folha.uol.com.br/folha/cotidiano/ ult95u550240.shtml) e o Observatório das Favelas (http:// www.observatoriodefavelas.org.br/observatoriodefavelas/ noticias/mostraNoticia.php?id_content=517).

7 A esse respeito ver Baptista (2001) e a discussão acerca da visita de um grupo de sem-teto ao Shopping Center Rio Sul, na zona sul carioca. O registro em áudio dessa cena pode ser encontrada no documentário Encontro com Milton Santos ou O Mundo Global Visto do Lado de Cá (2007), de Sílvio Tendler. Lembro-me também da fala de um amigo negro ao discutirmos racismo, quando este reproduz o jargão da PM, segundo a qual elemento cor-padrão em atitude suspeita significaria um negro andando em frente a um shopping center..

\section{Take 2: Subjetividade-Ciborgue}

E que maquinações subjetivas estão em curso nesses novos tempos? A subjetividade aqui não é pensada como uma essência interiorizada ou passível de ser reduzida ao âmbito individual. A subjetividade, como nos fala Guattari, é de natureza maquínica e produzida no registro do social (GUATTARI; ROLNIK, 1986).

Ao falar de subjetividade, então, referimonos a modos de existência imanentes aos modos de organização da vida social. Nossos modos de pensar, de sentir, de aprender, de trabalhar, de nos relacionar, são engendrados na cidademundo. A cidade-mundo também é, por sua vez, efeito dos modos como nos relacionamos com o espaço, com as outras pessoas, com o modo de produção capitalista, com a vida.

Não existe uma subjetividade do tipo 'recipiente' em que se colocariam coisas essencialmente exteriores, as quais seriam 'interiorizadas'. As tais 'coisas' são elementos que intervêm na própria sintagmática da subjetivação inconsciente. São exemplos de coisas desse tipo: um certo jeito de utilizar a linguagem, de se articular ao modo de subjetivação coletiva (sobretudo da mídia); uma relação com o universo das tomadas elétricas, nas quais se pode ser eletrocutado; uma relação com o universo de circulação na cidade. Todos esses são elementos constitutivos da subjetividade [...] (GUATTARI, 1986, p. 34, grifo nosso).

Guattari (1986) chama de subjetividade capitalística8 um tipo de produção subjetiva hegemônica na contemporaneidade, que se caracteriza por uma intensa individualização, culpabilização e infantilização.

A individualização produzida pelo capitalismo nos faz acreditar que somos seres dotados de uma interioridade própria, uma identidade privada absolutamente original e singular, que se constitui naturalmente em uma relação de diferenciação com tudo que está fora (o mundo, a coletividade, a cidade). O fora é um risco e dele devemos nos proteger. Guattari (1987)

8 Guattari (1987) criou este conceito quando ainda vivíamos em um mundo marcado pela oposição capitalismo versus socialismo e prevalecia nos movimentos de esquerda inspirados pelo marxismo a idéia de uma sobredeterminação da infra-estrutura econômica sobre a superestrutura. Com esta expressão quis chamar a atenção para o fato que a subjetividade capitalística não é mero efeito do modo de produção econômico, mas é um fenômeno complexo, que envolve diferentes universos (econômicos, mas também semióticos, icônicos, culturais, etc.). 
chama a atenção para o fato de que o indivíduo é um efeito deste modo de subjetivação e, diferentemente do que propõe um certo ideário liberal-psicologizante, é produzido de forma serializada, massificada, fabril. Portanto, nenhuma contradição entre individualização e massificação, ambas constituem faces da mesma moeda. Ao mesmo tempo em que vivenciamos nossa identidade como única, miIhares de pessoas no mundo também têm os mesmos desejos íntimos, não porque tenham a mesma estrutura psíquica, mas porque são subjetivados pelas grandes máquinas do capital, em especial a mídia. A individualização é, portanto, um modo de subjetivação característico do capitalismo e não uma natureza inscrita no psiquismo humano. Cabe ressaltar que este modo de experimentarmos a subjetividade nos habilita imediatamente a ocuparmos um lugar na engrenagem do consumo.

A culpabilização relaciona-se ao processo de individualização e faz com que, a partir da desarticulação das redes que nos constituem, fiquemos fragilizados na relação estabelecida com os sistemas de disciplinarização, de hierarquização social e passemos a nos sentir como responsáveis absolutos pelo que nos acontece: se estamos desempregados, a questão não diz respeito à crise do trabalho no mundo atual, mas ao fato de não sermos suficientemente competitivos para o mercado; se nos endividamos é porque temos compulsão e não porque somos subjetivados a consumir sempre mais, movidos pela idéia de que é isso que dá sentido à vida...

A noção de responsabilidade individuada é uma noção tardia, assim como as noções de erro e de culpabilidade interiorizada. Num certo momento, se assistiu a um confinamento generalizado das subjetividades, a uma separação dos espaços sociais e a uma ruptura de todos os antigos modos de dependência. Com a Revolução Francesa, não só todos os indivíduos tornaram-se de direito - e não de fato - livres, iguais e irmãos (e, além disso, perderam suas aderências subjetivas aos sistemas de clãs, de grupos primários) mas também tiveram de prestar contas a leis transcendentais, leis da subjetividade capitalística. Nessas condições foi necessário fundar em outras bases, o sujeito e suas relações: a relação do sujeito com o pensamento (o cogito cartesiano), a relação do sujeito com a lei moral (o numen kantiano), a relação do sujeito com a natureza (outro sentimento em relação à natureza e outra concepção de natureza), a relação com o outro (a relação do outro como objeto). É nessa deriva geral dos modos territorializados da subjetividade que se desenvolveram não só teorias psicológicas referentes às faculdades da alma, como também uma reescrita permanente dos procedimentos de subjetivação no campo geral das transformações sociais. (GUATTARI, 1986 , p. 35-36)

Por fim, a infantilização faz com que pensemos ser incapazes para gerir a vida, sem a mediação do Estado. Assim, não sabemos mais criar nossos filhos sem as prescrições da Medicina, da Psicologia e da Pedagogia; não conseguimos nos relacionar conosco e com o mundo de forma eficiente se não lemos os livros de auto-ajuda, aceitamos as prescrições veiculadas na mídia (de Super Nanny a Dr. Bactéria...) ou fazemos análise; não conseguimos mais pensar se não tomamos como base o saber cientificamente legitimado ou as verdades produzidas pelos equipamentos coletivos de enunciação... a heterogestão é a tônica deste modo de vida.

Apesar da força dos modos de subjetivação hegemônicos, continuam sendo produzidas estratégias de resistência e de invenção de uma vida que escape à domesticação do capital. Se a subjetividade não é uma essência inviolável, mas permanentemente produzida no campo sócio-histórico, isso significa que ela pode ser produzida de outras formas. É neste ponto que Guattari (1986) propõe a noção de processos de singularização ou revoluções moleculares, que seriam processos de reapropriação dos elementos da subjetividade e de ruptura com a subjetividade capitalística. Estes processos sempre se dão em conexão com o fora, com a cidade-mundo: esta é sua condição de possibilidade. Para tanto, é necessário criar modos de referências singulares, que ganham consistência no plano do coletivo. "A revolução molecular consiste em produzir as condições não só de uma vida coletiva, mas também da encarnação da vida para si próprio, tanto no campo material, quanto no campo subjetivo." (GUATTARI, 1986, p. 46)

Portanto, a subjetividade, também tomada como uma máquina é forjada na combinação de diferentes elementos. Não haveria, portanto, uma natureza ou essência humana, mas uma espécie híbrida. Feixes entrelaçados de carbono e silício são os novos habitantes da sociedade de controle.

[...] uma forma-Homem só aparece em condições muito especiais e precárias: é o que Fou- 
cault analisa em As Palavras e as Coisas, como a aventura do século XIX, em função das novas forças com as quais as do homem se combinam naquele momento. Ora, hoje todo mundo diz que o homem entra ainda em relação com outras forças (o cosmos no espaço, as partículas na matéria, o silício na máquina...): uma nova forma nasce daí, que já não é mais a do homem [...] (DELEUZE, 1992, p. 146).

Essa forma pós-humana talvez possamos chamá-la subjetividade-ciborgue, para indicarmos o caráter híbrido e mutante de sua composição, imediatamente conectada às grandes e minúsculas máquinas, visíveis e invisíveis, atuais e virtuais, materiais e abstratas, máquinas contemporâneas que podem operar a favor e contra seu tempo.

O ciborgue nos força a pensar não em termos de 'sujeitos', de mônadas, de átomos ou indivíduos, mas em termos de fluxos e intensidades, tal como sugerido, aliás, por uma 'ontologia' deleuziana. O mundo não seria constituído, então, de unidades ('sujeitos'), de onde partiriam as ações sobre outras unidades, mas inversamente, de correntes e circuitos que encontram aquelas unidades em suas passagem. (TADEU, 2009, p. 14)

Ou ainda, como afirma Donna Haraway, em seu Manifesto Ciborgue:

No final do século $X X$, neste nosso tempo, um tempo mítico, somos todos quimeras, híbridos - teóricos e fabricados - de máquina e organismo; somos, em suma, ciborgues. O ciborgue é nossa ontologia: ele determina a nossa política. O ciborgue é uma imagem condensada tanto da imaginação quanto da realidade material: esses dois centros, conjugados, estruturam qualquer possibilidade de transformação histórica. (HARAWAY, 2009, p. 37)

Ciborgues não têm natureza ou caráter. Macunaímas pós-humanos abrem, entretanto, uma brecha para a construção de outras temporalidades, outros modos de vida, como sinaliza Haraway (2009). Desnaturados, sem pai, nem mãe, sem destino e sem rosto, essas figuras híbridas da subjetividade podem ser tomadas como pontos de proliferação de outros modos de existência em um combate que não se dá mais por oposições, mas por insurgências diferenciantes.

De uma certa perspectiva, um mundo de ciborgues significa a imposição final de uma grade de controle sobre o planeta; significa a abstração final corporificada no apocalipse da Guerra nas Estrelas - uma guerra travada em nome da defesa [...] de uma outra perspectiva, um mundo de ciborgues pode significar realidades sociais e corporais vividas, nas quais as pessoas não temam identidades permanentemente parciais e posições contraditórias. A luta política consiste em ver a partir de ambas as perspectivas ao mesmo tempo, porque cada uma delas revela tanto dominações como possibilidades que seriam inimagináveis a partir de outro ponto de vista. Uma visão única produz ilusões piores do que uma visão dupla ou do que a visão de um monstro de múltiplas cabeças. As unidades ciborguianas são monstruosas e ilegítimas: em nossos presentes circunstâncias políticas, dificilmente podemos ter mitos mais potentes de resistência e acoplamento. (HARAWAY, 2009, p. 46)

A subjetividade-ciborgue atualiza dominações e possibilidade, apontando para a complexidade desses nossos tempos e exigindo de nós novos instrumentos de análise e ferramentas conceituais capazes de tornar visíveis perspectivas antes insuspeitadas. Para tal empreitada podemos dispensar um olho de vidro despótico, como o de Lourenço, que tudo vê, mas talvez não seja prudente abrir mão de um olhar fugidio, (d)esta-mira capaz de reiventar o real, forçando-nos a ir mais além.

\section{Take 3: Lourenço e 0 Cheiro do Ralo}

A cidade na qual Lourenço vive tem contornos definidos: é possível acompanhar uma sucessão de vazios e paisagens desabitadas nos deslocamentos feitos diariamente entre a casa e o trabalho. Ninguém tem nome próprio, todos compõem a paisagem imóvel que testemunha a vida do protagonista. Nem mesmo a feliz proprietária da bunda avidamente desejada tem um nome, ele é impronunciável: reduz-se a uma mímica labial, dando uma tessitura onírica para a personagem.

Toda e qualquer presença da cidade, do mundo em sua alteridade, deve ser banida como sujeira indesejável. O mendigo que tenta construir uma história (ainda que provisória) na fachada da loja de penhores tem seu destino selado pela truculência bordô do segurança e o ralo é vedado com cimento, 
para evitar presenças impossíveis de serem sobrecodificadas pela axiomática do capital. A história é banida da vida e instaura-se um presente permanente, sem obstáculos para o fluxo contínuo do consumo. Ao fazer uma crítica à noção de identidade, compreendida como uma essência a ser historicizada e superada, em prol de uma perspectiva ampliada de relação com o outro, Olgária Matos afirma:

Trata-se de um 'eterno presente', o do vazio, pois o pânico não reconhece a passagem do tempo com o que a noção de futuro - como advento do 'novo', do 'miraculoso' - é confiscada. O futuro é visto como previsível e controlável e é evocado como necessitarismo a fim de responder às contingências do presente coisificado, o que destitui o tempo do agir histórico. (MATOS, 2006, p. 60)

A vida só parece existir como uma sucessão de negociações, algumas enfadonhas, outras excitantes, mas todas ancoradas em Lourenço-buraco, por onde parece esvair toda a merda resultante desta máquina, que reduz tudo à mercadoria. Ao conseguir comprar a bunda, Lourenço afirma, entre feliz e aliviado: "E assim mais uma coisa - a bunda - se torna como as coisas que eu tranco na sala ao lado [...]" (O CHEIRO..., 2007).

Peter Stallybrass (2004), ao discutir o fetiche da mercadoria em Marx, aponta para a operação capitalista de produzir a mercadoria não como uma "[...] particularidade material, mas como um valor suprassensível [...]" (STALLYBRASS, 2004, p. 55). Quando tudo se equivale à mercadoria, ocorre uma desvalorização do real, do material, do objeto concreto, pois tudo passa a ser mensurado a partir de uma equivalência universal ao capital: "Rodeados como estamos por uma extraordinária abundância de materiais, seu valor deve ser incessantemente desvalorizado e substituído [...]" (STALLYBRASS, 2004, p. 20). Reduzidas à condição de mercadoria todas as coisas encontram seu lugar no mundo como uma equivalência.

Talvez a loja de Lourenço seja uma alegoria da vida que vêm sendo produzida, daquilo em que vimos nos tornando a partir dos modos de subjetivação contemporâneos. A subjetividade capitalística é a mercadoria invisível da loja de penhores e Lourenço-ciborgue reedita a cada cena o vazio que o constitui. Sem natureza e sem pai, Lourenço opera por fragmentos, colecionando objetos, buscando construir al- gum plano de consistência para uma vida que, excretada pela máquina capitalística (vida de merda?) parece incapaz de compor qualquer território existencial. Vida que é fluxo vertiginoso do capital que só se detém aos solavancos, reduzindo o desejo a mais uma mercadoria: a bunda.

Entretanto, a vida-feita-cheiro, em sua imaterialidade, desestabiliza as certezas de Lourenço. Ele afirma em certo momento: "É tão difícil acontecer uma coisa que eu não tinha previsto [...]" (O CHEIRO..., 2007). Talvez daí venha sua fascinação pelo olho-que-já-viutudo, já que não há surpresas para este olhoprótese que Lourenço incorpora a seu corpo, a fim de reassegurar sua posição de controle, estremecida pelo cheiro incontrolável que insiste em sair do ralo. O olho-que-já-viu tudo parece saber de mundos que existem além da Loja de Penhores, parece ter visto coisas que não cabem na estreita vida do ciborgue-marrom. Olho-panóptico ou olho-luneta, descobridor de mundos? Talvez, um pouco dos dois...

Em um momento que Ihe escapa, Lourenço afirma: "De todas as coisas que tive, as que mais me valeram, as que mais sinto falta, são as coisas que não se pode tocar, são as coisas que não estão ao alcance de nossas mãos. São as coisas que não fazem parte do mundo da matéria." (O CHEIRO..., 2007) Essas coisas estranhas, irredutíveis à condição de mercadoria, revelam a fragilidade de Lourenço, a qual é, paradoxalmente, sua maior força, pois é o que o permite esboçar alguma resistência em meio à sujeição (quase) absoluta aos processos de subjetivação capitalísticos. Lourenço sente falta do que escapa às reiteradas tentativas de aprisionamento nos fluxos de equivalência capitalísticas e, nesse momento, experimenta outros agenciamentos, que apesar de fugidios, Ihe fazem sentir que a vida pode ter outros cheiros.

Lourenço não se mistura à cidade-mundo. Ela aparece no filme como uma cidade-fantasma, feita de espaços e percursos previsíveis e desabitados. Quando tropeça nela, ao encontrar um mendigo na porta de sua loja, pede ao segurança que limpe a área. Nesse momento, inicia uma conversa onde define o que seja o lixo: "O Homem é o Deus do Conforto. O lixo é o troco. O Homem criou o lixo pra ocupar os desocupados." (O CHEIRO..., 2007) Não há lugar neste mundo para o que não é passível de ser codificado segundo a lógica do capital. 
Tudo tem seu lugar. Nem o lixo sobra, nem surpreende.

O filme termina com Lourenço sendo assassinado pela vida. Uma forma de vida estranha, não a vida plastificada que nos acostumamos a ver na TV, mas um trapo de vida, que já parecia completamente escravizado pela droga: uma moça magérrima que vai sempre à Loja vender pequenos objetos para se drogar. Em uma dessas vezes, sem ter o que vender, Lourenço propõe-Ihe que venda sua nudez e ela se despe, enquanto o mercador se masturba e goza ao realizar mais uma compra. A moça, constrangida, submetida à vergonha de ter virado mercadoria, sai transtornada e retorna, armada, para um acerto final. É essa vida esquálida, que ao afirmar-se em sua precariedade, mata a vida vazia, a vida oca do mercador.

E nessa cena final, Lourenço se arrasta até o ralo para sorver o seu cheiro". "O cheiro do ralo é como se eu me reencontrasse. $O$ cheiro é meu. Foi ele quem me trouxe a bunda. É um presente do inferno." "Eu vou me reconectar com o meu Eu." (O CHEIRO..., 2007) Tudo começa e termina no ralo. Não há lugar para a cidade-mundo, não há espaço-tempo para uma vida não colonizada pelo capital. $A$ vida é dura.

\section{Take 4: Estamira e os Odores do Mundo}

Estamira (2006) está "[...] além-dos-além $[\ldots]^{\prime 10}$. A cidade-mundo se mistura a essa muIher, louca, feiticeira, avogada ${ }^{11}$, catadora de lixo, mãe, dentre tantas outras coisas, para contar a sua história. O documentário começa com uma sucessão de imagens: a placa de madeira improvisada que contém o nome da rua onde fica a casa da personagem, objetos espalhados pelo quintal, Estamira subindo no ônibus que parece levá-la para algum lugar distante. Logo descobrimos tratar-se do Lixão de Gramacho. Tão longe, tão perto.

9 Apresento a seguir, entre aspas, falas de Lourenço em partes diferentes do filme.

10 Daqui em diante, o que estiver entre aspas também refere-se a falas da personagem.

11 Avogada (advogada) é uma das inúmeras formas como Estamira refere-se a si mesma.
A falta de ar que nos acompanhou em $O$ Cheiro do Ralo, vai dando lugar a outras sensações ao adentrarmos no universo de Estamira. Vastas e imprecisas sensações, no entanto uma parece ser mais clara: aqui conseguimos respirar, mesmo diante de cenas nada confortáveis, nas quais se misturam urubus, cadáveres, miséria, lixo, lixo, lixo, gente. Há cenas belas também: amigos conversando no Lixão ao fim de um dia de trabalho, sacos plásticos dançando no céu de um azul suave, um olhar terno de Estamira para sua filha caçula, um gato que explora os desvãos do telhado.

A diversidade da vida se apresenta em cores e cheiros fortes na tela. Diferente do cheiro do ralo, o fedor aqui é público e compõe com a paisagem uma vida para esta mulher fascinante, que, aos 63 anos, nos adverte sobre as astúcias do trocadilo, o esperto ao contrário. Este inimigo a ser combatido, que para Estamira responde pelo nome de Deus, não parece estar em um plano metafísico, já que as sucessivas tentativas de totalização e aplainamento da subjetividade e da cidade, que inevitavelmente convergem todas para um único e solitário ralo, nos espreitam a cada esquina...

Ela afirma: "A minha missão, além de ser Estamira, é revelar a verdade... ensinar a mostrar o que eles não sabem. [...] Olha, lá: os morros, as serras, as montanhas, a paisagem [...] a Estamira, esta mira, esta serra. Estamira tá em tudo quanto é canto, em todo lado [...]" (ESTAMIRA, 2006). Talvez o que Estamira esteja a nos dizer é que ela não cabe num único corpo, numa camisa-de-força identitária: Estamira é muitas e sua loucura explode as tentativas de fixação do capital. E ela só consegue criar um outro corpo e uma outra vida para si ao se lançar no coletivo, ao tecer com o Lixão, com sua família, com a história, com a cidade-mundo, modos singulares de existência.

É a partir das composições que engendra com a cidade-mundo, que ela a transforma e é por ela transformada. Ao fazer do lugar destinado ao refugo da sociedade de consumo, o território a partir do qual reconstrói a sua vida, Estamira faz do Lixo não só o cemitério dos restos, mas espaço de articulação de resíduos, de criação da vida. Nesse movimento constitui um plano de referência que a permite transitar por diferentes possibilidades subjetivas, sem se deixar aprisionar a quaisquer identidades pré- 
estabelecidas: a de doente mental, a de miserável, a de catadora de lixo, a de blasfema. Tente responder: Quem é Estamira?

Estamira é um acontecimento.

É preciso entender por acontecimento não uma decisão, um tratado, um reino, ou uma batalha, mas uma relação de forças que se inverte, um poder confiscado, um vocabulário retomado e voltado contra seus utilizadores, uma dominação que se enfraquece, se distende, se envenena e uma outra que faz sua entrada, mascarada. As forças que se encontram em jogo na história não obedecem nem a uma destinação, nem a uma mecânica, mas ao acaso da luta. (FOUCAULT, 1989 , p. 28)

O acontecimento-Estamira implode o modo de subjetivação capitalístico e nos faz embarcar em modos de experimentação da vida que conseguem, mesmo diante da mais intensa precariedade material, fazer derivar as ruas e os caminhos, ao instaurar formas singulares de sociabilidade, de existência e de apropriação e circulação na cidade. Subjetividade-ciborgue, Estamira implode os modos de existência individualizados, responsáveis e tutelados que nos lançam para o fundo do ralo, ao retraçar coordenadas existenciais marcadas pelos saberes psi, pela asfixiante ausência de um Fora, pelo modo de produção capitalístico.

Estamira é uma mãe não-materna, uma louca-lúcida que luta contra as tentativas de tutela bioquímica e subjetiva, uma poeta sem rimas certas, uma errante em territórios conhecidos. Misturando fios intensivos de diferentes matérias, ela nos mostra como maquinar uma vida que se insurge nas malhas do capitalismo. "Esses ciborgues da vida real [...] estão ativamente reescrevendo os textos de seus corpos e sociedades. A sobrevivência é o que está em questão nesse jogo de leituras." (HARAWAY, 2009, p. 90)
O lixo que, com todas a suas misturas e impurezas, era algo a ser banido para o asséptico Lourenço, é tomado aqui em toda a sua potência de criação. Assim, Estamira, cuja missão no mundo é nos salvar, revela:

Isso aqui é um depósito dos restos. Às vezes é só resto, às vezes vem também descuido. Resto e descuido. Quem revelou o Homem como único condicional ensinou ele a cuidar das coisas. E cuidar das coisas é proteger, lavar, limpar e usar mais [...] o quanto pode. (ESTAMIRA, 2006)

Os restos são o rastro de um modo de vida em que todo excesso é lixo. O lixo, o que é descartado pela sociedade de consumo, pelo capitalismo da vez, é matéria de agenciamento para Estamira-ciborgue reconstruir-se enquanto dança, trabalha e reinventa novos modos de viver. Entre restos e descuidos é possível ganhar a vida, fazer amigos, interagir com a beleza de um céu iluminado por raios e esgarçado por trovões.

Os fedores do Lixão, o mal-cheiro da cidade-mundo, nos parecem mais respiráveis que o cheiro do ralo. Talvez porque nos abra para possibilidades insuspeitadas nas entrelinhas do cotidiano, talvez porque ao lado do Lixo possamos imaginar um mar, talvez porque ao causar uma leve aceleração no peito, revele que ainda pulsamos...

Talvez assim, passando a ver o mundo com esta mira, possamos desaprender a copiar as hipocrisias e mentiras charlatais que nos fazem crer num mundo sem futuro, num tempo sem história, numa vida sem invenção, numa cidade sem encontro, num verbo sem delírio, numa existência sem cheiro. Quem sabe aí, possamos ouvir uma voz que nos salve do ralo ao dizer que não somos mesmo um robô sangüíneo, inaugurando passagens para vertigens ciborgueanas...

\section{Referências}

BAPTISTA, L.A. Cidades, Lugares, Sujeitos: contribuições da literatura e da política. In: FRIGOTTO, G.; CIAVATTA, M. (Org.). Teoria e Educação no Labirinto do Capital. Petrópolis: Vozes, 2001. P. 194-203

BAPTISTA, L.A. Combates Urbanos: a cidade como território de criação. In: GUARESCHI, N. (Org.). Estratégias de Invenção do Presente: a Psicologia Social no contemporâneo. Porto Alegre: Edipucrs, 2004. P. 172-177.

O CHEIRO do Ralo. Direção: Heitor Dhalia. [São Paulo]: Universal Pictures, 2007. Color. Duração: 112min. 
COSTA, R. Sociedade de Controle. In: CRUZ, J. (Org.). Gilles Deleuze: sentidos e expressões. Rio de Janeiro: Ciência Moderna, 2006. P. 31-46.

DELEUZE, G. Um Retrato de Foucault. In: DELEUZE, G. Conversações. Rio de Janeiro: Ed. 34, 1992. P. 127147.

DELEUZE, G. Post-scriptum Sobre as Sociedades de Controle. In: DELEUZE, G. Conversações. Rio de Janeiro: Ed. 34, 1992a. P. 219-226.

DELEUZE, G.; GUATTARI, F. O Anti-Édipo: capitalismo e esquizofrenia. Lisboa: Assírio e Alvim, 1976.

ENCONTRO com Milton Santos, ou, O Mundo Global Visto do Lado de Cá. Direção: Sílvio Tendler. Rio de Janeiro: Caliban Produções Cinematográficas, 2007. Color. Duração: 89min. Documentário.

ESTAMIRA. Direção: Marcos Prado. Rio de Janeiro: Riofilme/Zazen Produções Audiovisuais, 2006. Color, pb ; 35mm. Duração: 115min. Documentário.

FONSECA, R. A Arte de Andar nas Ruas do Rio de Janeiro. In: FONSECA, R. Romance Negro e Outras Histórias. São Paulo: Companhia das Letras, 1992. P. 356-391.

FOUCAULT, M. Nietzsche, a Genealogia e a História. In: FOUCAULT, M. Microfísica do Poder. Rio de Janeiro: Graal, 1989. P. 15-38.

FOUCAULT, M. Vigiar e Punir: história da violência nas prisões. Petrópolis: Vozes, 1989a.

FOUCAULT, M. A Vida dos Homens Infames. In: FOUCAULT, M. Ditos e Escritos. Rio de Janeiro: Forense Universitária, 2003. V. 5.

GOMES, R.C. Cenas Urbanas: identidades em fragmentos e crise da representação. In: PEREIRA, M.; GOMES, R.C.; FIGUEIREDO, V.L.F. (Org.). Comunicação, Representação e Práticas Sociais. Rio de Janeiro: Ed. PUC-Rio; Idéias e Letras, 2004. P. 201-217.

GUATTARI, F. O Capitalismo Mundial Integrado e a Revolução Molecular. In: GUATTARI, F. Revolução Molecular: pulsações políticas do desejo. São Paulo: Brasiliense, 1987. P. 211-226.

GUATTARI, F. Milhões e Milhões de Alices no Ar. In: GUATTARI, F. Revolução Molecular: pulsações políticas do desejo. São Paulo: Brasiliense, 1987a. P. 56-63.

GUATTARI, F. Restauração da Cidade Subjetiva. In: GUATTARI, F. Caosmose: um novo paradigma estético. Rio de Janeiro: Ed. 34, 1992. P. 167-180.

GUATTARI, F.; ROLNIK, S. Micropolítica: cartografias do desejo. Petrópolis: Vozes, 1986.

HARAWAY, D. Manifesto Ciborgue: ciência, tecnologia e feminismo-socialista no final do século XX. In: TADEU, T. (Org.). Antropologia do Ciborgue: as vertigens do pós-humano. Belo Horizonte: Autêntica, 2009. P. 33-118.

HARDT, M. A Sociedade Mundial de Controle. In: ALLIEZ, E. (Org.). Gilles Deleuze: uma vida filosófica. Rio de Janeiro: Ed. 34, 2000. P. 357-372.

MATOS, O. A Identidade: o estrangeiro em nós. In: MATOS, O. Discretas esperanças: reflexões filosóficas sobre o mundo contemporâneo. São Paulo: Ed. Nova Alexandria, 2006. P.51-66.

PEIXOTO, N.B. As Máquinas de Guerra Contra os Aparelhos de Captura. In: PACHECO, A.; VAZ, P. (Org.). Vozes no Milênio: para pensar a globalização. Rio de Janeiro: Gryphus; Museu da República, 2002. P. 99-114.

SANTOS, M. Quem Tem Medo das Grandes Cidades? In: SANTOS, M. O País Distorcido: o Brasil, a globalização e a cidadania. São Paulo: Publifolha, 2002. P. 123-125.

STALLYBRASS, P. O Casaco de Marx: roupas, memória, dor. Belo Horizonte: Autêntica, 2004.

TADEU, T. (Org.). Antropologia do Ciborgue: as vertigens do pós-humano. Belo Horizonte: Autêntica, 2009. 
VIRILIO, P. O Espaço Crítico. Rio de Janeiro: Ed. 34, 1993.

Recebido em março de 2010.

Aprovado para publicação maio de 2010.

Psicóloga, Doutora em Psicologia Social pela Universidade do Estado do Rio de Janeiro/Rio de Janeiro-RJ/Brasil.

Email: arosacs@uol.com.br 